\title{
ISOLASI DAN IDENTIFIKASI SENYAWA METABOLIT SEKUNDER EKSTRAK METANOL DAUN KELOR (Moringa oleifera Lamk.)
}

\author{
Yuszda K. Salimi, Nurhayati Bialangi, Saiman \\ Jurusan Kimia, Universitas Negeri Gorontalo \\ Email : Yuszdasalimi23@gmail.com
}

\begin{abstract}
A study has been conducted on the isolation and identification of secondary metabolite compounds from methorol extract of kelor leaf (Moringa oleifera Lamk.). This study aims to isolate and identify secondary metabolite compounds from leaf kelur methanol extract. Moringa leaf was macerated with methanol and obtained a yield of $16.7 \%$ methanol extract. The extract of methanol separated by column chromatography yielded 272 fractions. The fraction was purified and analyzed by thin layer chromatography using eluent n-hexane: ethyl acetate (7: 3) and obtained stain spots with Rf (0.61) and (0.47). Phytochemical results of positive isolates on flavonoids test. The results of identification using UV-Vis spectrophotometry and infrared spectrophotometry is a flavonoid compound. The identification using UV-Vis spectrophotometry yields / absorbing bands at $250 \mathrm{~nm}$ wavelength. The absorption at $250 \mathrm{~nm}$ wavelength is suspected because of the non-bonding electron transition to the $\sigma$ anti-bonding orbital $\left(n \rightarrow \sigma{ }^{*}\right)$ by an unconjugated ausochrome suspected to be a hydroxyl functional $(\mathrm{OH})$ group. Identification using infrared (IR) spectrophotometry showed the presence of a bound $\mathrm{OH}$ function group, $\mathrm{C}=\mathrm{O}, \mathrm{C}=\mathrm{C}$ aromatic, $\mathrm{C}-\mathrm{H}$ aliphatic, $\mathrm{C}-\mathrm{O}$ alcohol and $=\mathrm{C}-\mathrm{H}$ aromatic.
\end{abstract}

Keywords: Kelor, methanol, isolation, identification, secondary metabolite

\begin{abstract}
Abstrak
Telah dilakukan penelitian tentang isolasi dan identifikasi senyawa metabolit sekunder dari ekstrak metanol daun kelor (Moringa oleifera Lamk.). Penelitian ini bertujuan untuk mengisolasi dan mengidentifikasi senyawa metabolit sekunder dari ekstrak metanol daun kelor. Daun kelor dimaserasi dengan metanol dan diperoleh rendemen ekstrak metanol 16,7\%. Ekstrak metanol dipisahkan dengan kromatografi kolom menghasilkan 272 fraksi. Fraksi dimurnikan dan dianalisis dengan kromatografi lapis tipis menggunakan eluen n-heksan:etil asetat (7:3) dan diperoleh
\end{abstract}


bercak noda dengan $\operatorname{Rf}(0,61)$ dan $(0,47)$. Hasil uji fitokimia isolat positif terhadap uji flavonoid. Hasil identifikasi mengunakan spektrofotometri UV-Vis dan spektrofotometri inframerah merupakan senyawa flavonoid. Identifikasi menggunakan spektrofotometri UV-Vis menghasilkan I pita yang menyerap pada panjang gelombang $250 \mathrm{~nm}$. Serapan pada panjang gelombang $250 \mathrm{~nm}$ di duga karena adanya transisi elektron yang tidak berikatan ke orbital $\sigma$ anti-ikatan $\left(n \rightarrow \sigma^{*}\right)$ oleh suatu ausokrom yang tidak terkonjugasi yang diduga merupakan gugus fungsional hidroksil $(\mathrm{OH})$. Identifikasi menggunakan spektrofotometri inframerah (IR) menunjukkan adanya gugus fungsi $\mathrm{OH}$ terikat, $\mathrm{C}=\mathrm{O}, \mathrm{C}=\mathrm{C}$ aromatik, $\mathrm{C}-\mathrm{H}$ alifatik, $\mathrm{C}-\mathrm{O}$ alkohol dan $=\mathrm{C}-\mathrm{H}$ aromatik.

Kata kunci: Kelor, metanol, isolasi, identifikasi, metabolit sekunder

\section{PENDAHULUAN}

Indonesia memiliki sumber daya alam organik sangat berlimpah dan mengandung jutaan senyawa kimia. Tumbuhan dapat berpotensi sebagai pengobatan penyakit karena mengandung senyawa metabolit sekunder. Secara totalitas tumbuhan di Indonesia, sebagian besar belum diteliti kandungan kimianya. Belum adanya bukti secara ilmiah menyebabkan tumbuhan tertentu tidak dimanfaatkan secara maksimal dan keberadaannya tumbuh sebagai tumbuhan liar.

Penelitian khusus untuk mengisolasi senyawa bahan alam sangat diperlukan untuk mendapatkan senyawa metabolit sekunder tertentu. Salah satu contoh tumbuhan yang biasanya digunakan sebagai pengobatan tradisional adalah tumbuhan kelor. Masyarakat Indonesia khususnya masyarakat pedesaan telah lama memanfaatkan kelor baik sebagai obat tradisional, sebagai sayuran, maupun makanan ternak. Keberadaan tumbuhan kelor sangat mudah didapatkan di seluruh wilayah Indonesia tidak terkecuali di daerah Gorontalo. Salah satu bagian tumbuhan kelor yang banyak dikonsumsi adalah bagian daun.

Penelitian tentang daun kelor
dilaporkan Rohyani, dkk. (2015)
menunjukkan bahwa hasil skrining
fitokimia dari daun kelor mengandung
senyawa metabolit sekunder di


antaranya flavonoid, alkaloid, steroid, tanin, saponin, antrakuinon dan terpenoid. Selain itu, Lutfiana (2013), dari hasil penapisan fitokimia fraksi etil asetat daun kelor mengandung senyawa flavonoid, saponin dan tanin. Dari kedua hasil penelitian tersebut membuktikan bahwa daun kelor mengandung senyawa metabolit sekunder.

\section{METODE PENELITIAN}

\section{Alat dan Bahan}

Alat yang digunakan adalah satu set peralatan kromatografi, lampu UV, spektrofotemeter UV-Vis dan Infrared (IR).

Bahan yang digunakan adalah aquades $\left(\mathrm{H}_{2} \mathrm{O}\right)$, metanol $\left(\mathrm{CH}_{3} \mathrm{OH}\right)$, etil asetat $\left(\mathrm{C}_{3} \mathrm{H}_{8} \mathrm{O}_{2}\right)$, n-heksana $\left(\mathrm{C}_{6} \mathrm{H}_{14}\right)$, aseton $\left(\mathrm{C}_{3} \mathrm{H}_{6} \mathrm{O}\right)$, kloroform $\left(\mathrm{CHCl}_{3}\right)$, asam sulfat $\left(\mathrm{H}_{2} \mathrm{SO}_{4}\right)$, pereaksi Mayer, pereaksi Dragendrof, pereaksi Wagner, pereaksi Hager, silica gel 60 (70-230 Mesh), plat $\mathrm{KLT} \quad \mathrm{GF}_{254}$., serbuk magnesium $(\mathrm{Mg})$, asam klorida $(\mathrm{HCl})$, asam asetat $\left(\mathrm{CH}_{3} \mathrm{COOH}\right)$, dan natrium hidroksida $(\mathrm{NaOH})$.
Sampel penelitian ini adalah daun kelor. Lokasi pengambilan sampel di kota Gorontalo. Sampel dideterminasi di Laboratorium Biologi Universitas Negeri Gorontalo (UNG).

\section{Prosedur Penelitian}

\section{Preparasi sampel}

Sampel daun kelor segar
dikeringkan dengan cara diangin-
anginkan selama \pm 4 hari. Daun kelor
kering dirajang sampai menjadi serbuk
kasar dan dihitung rendemennya.

\section{Skrining fitokimia}

Skrining fitokimia secara kualitatif merupakan uji pendahuluan yang bertujuan untuk mengetahui senyawa metabolit sekunder yang terdapat pada ekstrak metanol. Skrining fitokimia terdiri dari uji flavonoid, alkaloid, saponin, steroid dan triterpenoid dengan metode Harborne, 1987.

\section{Kromatografi lapis tipis}

Kromatografi lapis tipis dilakukan untuk melihat pola kromatogram komponen senyawa yang terkandung 
dalam ekstrak metanol. Pada kromatografi lapis tipis dilakukan dengan prinsip trial and error guna mencari eluen yang memberikan pemisahan yang baik. Analisis kromatografi lapis tipis dilakukan menggunakan fase diam plat silika gel $60 \mathrm{GF}_{254}$ dengan fase gerak menggunakan beberapa perbandingan eluen untuk mencari pemisahan yang baik.

\section{Kromatografi kolom}

Kromatografi kolom menggunakan fase diam menggunakan silika gel 60 (70-230 Mesh) dan fase gerak menggunakan eluen secara bergradien mulai dari n-heksan 100\% hingga etil asetat $100 \%$ dan dilanjutkan dengan fase gerak etil asetat-metanol dengan komposisi etil asetat 100\% hingga metanol $100 \%$ dengan kenaikan kepolaran pelarut sebesar $10 \%$. Hasil elusi ditampung menggunakan botol vial sebagai fraksi.

\section{Uji kemurnian isolat}

Uji kemurnian isolat menggunakan teknik kromatografi lapis tipis (KLT)..

\section{Uji fitokimia isolat}

Uji fitokimia isolat terdiri dari uji flavonoid, alkaloid, dan triterpenoid. Uji keberadaan senyawa flavonoid dari isolat digunakan uji Wilstatter. Isolat ditambahkan 2-4 tetes $\mathrm{HCl}$ pekat dan serbuk Mg. Perubahan warna terjadi diamati dari kuning tua menjadi orange atau merah (Achmad, 1986).

\section{Identifikasi senyawa}

Identifikasi senyawa dilakukan dengan menganalisis ciri spektra hasil spektrofotometri UV-Vis dan spektrofotometri inframerah (IR). Isolat relatif murni dianalisis dengan instrumen spektrofotometer UV-Vis dan spektrofotometer inframerah (IR). Data yang diperoleh berupa spektra diinterpretasi untuk memperoleh data spektra senyawa yang digunakan untuk menentukan karakter dari senyawa yang terdapat dalam isolat.

\section{HASIL DAN PEMBAHASAN}

Hasil determinasi, kelor memiliki nama Moringa oleifera Lamk. Daun kelor kering $760 \mathrm{~g}$ dirajang sampai menjadi serbuk kasar dengan rendemen $21,74 \%$. Serbuk kasar daun 
dimaserasi menggunakan pelarut

metanol. Proses maserasi dilakukan selama $3 \times 24$ jam dan penyaringan dilakukan setiap 1x24 jam. Maserat total yang diperoleh dievaporasi menggunakan vacum rotary evaporator pada suhu $40^{\circ} \mathrm{C}$. Evaporasi bertujuan untuk memisahkan pelarut dengan ekstrak. Proses penguapan pelarut terjadi di bawah suhu titik didih pelarutnya sehingga tidak merusak senyawa aktif pada ekstrak. Hasil evaporasi adalah ekstrak kental metanol 111,89 g. Rendemen yang dihasilkan dari ekstrak kental metanol $16,7 \%$.

Ekstrak metanol diskrining fitokimia. Skrining fitokimia bertujuan untuk mengetahui kandungan senyawa kimia yang terdapat dalam ekstrak metanol. Skrining fitokimia yang dilakukan terdiri dari uji flavonoid, alkaloid, steroid, triterpenoid dan saponin.

Hasil skrining fitokimia ekstrak metanol menunjukkan hasil positif $(+)$ terhadap uji flavonoid, alkaloid, steroid, dan triterpenoid. Ekstrak metanol mengandung senyawa flavonoid yang ditandai dengan perubahan warna dari hijau tua menjadi hijau kekuningan dengan menggunakan pereaksi $\mathrm{HCl}+$ serbuk Mg. Perubahan warna tersebut diduga merupakan reaksi pembentukkan garam flavilium. Hal ini diperkuat oleh Prashant, 2011 dalam (Setyowaty, dkk., (2014) di mana asam klorida dan magnesium bereaksi membentuk gelembung-gelembung yang merupakan gas $\mathrm{H}_{2}$, sedangkan asam klorida dan logam magnesium pada uji ini berfungsi untuk mereduksi inti benzopiron yang terdapat pada struktur flavonoid sehingga terjadi perubahan warna menjadi merah atau jingga.

Analisis kromatografi lapis tipis pada ekstrak metanol dilakukan menggunakan fase gerak n-heksan : etil asetat (7:3). Ekstrak dilarutkan kedalam pelarut metanol. Pewarna yang digunakan adalah anisaldehida. Pelat yang sudah dielusi dideteksi dengan lampu UV 254 nm, 366 nm, dan sinar tampak. Berdasarkan hasil KLT pada ekstrak metanol, menunjukkan 9 bercak noda dengan nilai Rf $(0,05)$, 
$(0,13),(0,20),(0,31),(0,37), \quad(0,48), \quad$ yang memiliki kesamaan warna noda, $(0,63),(0,69)$ dan $(0,74)$.

jumlah noda dan nilai Rf dianggap satu

Selanjutnya ekstrak metanol $10 \mathrm{gr}$ dipisahkan dengan kromatografi kolom. Hasil pemisahan diperoleh 272 fraksi. Uji kemurnian terhadap senyawa hasil kromatografi kolom dilakukan fraksi. Warna noda diamati lebih teliti menggunakan lampu UV. Dari 272 fraksi yang memiliki profil bercak yang sama terdapat 13 gabungan fraksi (Gambar 1).

menggunakan teknik analisis

kromatografi lapis tipis (KLT). Fraksi

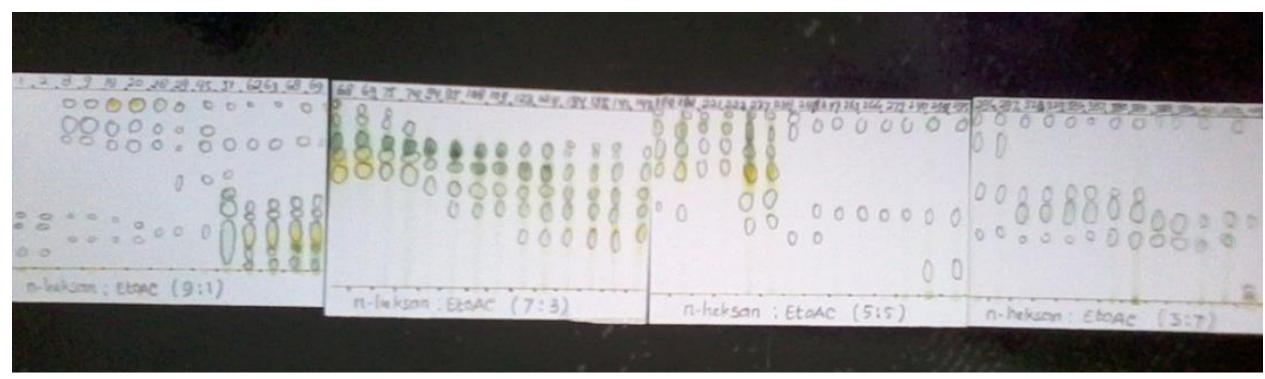

Gambar 1. Profil kromatogram lapis tipis fraksi hasil kromatografi kolom

\section{Uji kemurnian isolat}

Uji kemurnian isolat menggunakan teknik kromatografi lapis tipis. Kromatografi lapis tipis dilakukan untuk melihat pola kromatogram senyawa pada isolat. Analisis kromatografi lapis tipis dilakukan menggunakan fase diam plat silika gel $60 \mathrm{GF}_{254}$ dengan fase gerak $\mathrm{n}$-heksan : etil asetat (7:3). Isolat dilarutkan kedalam pelarut metanol. Pewarna yang digunakan adalah anisaldehida.
Pelat yang sudah dielusi dideteksi dengan lampu UV 254 nm, 366 nm, dan sinar tampak. Berdasarkan hasil $\mathrm{KLT}$ isolat nomor 28 , menunjukkan 2 bercak noda dengan $\operatorname{Rf}(0,61)$ dan $(0,47)$.

\section{Uji fitokimia isolat}

Hasil uji fitokimia isolat menunjukkan bahwa isolat positif $(+)$ terhadap uji flavonoid yang ditandai dengan munculnya gelembung pada 
saat penambahan serbuk $\mathrm{Mg}$ dan larutan menjadi berwarna merah. Perubahan warna merah pada uji flavonoid menunjukkan senyawa flavonoid. Senyawa golongan flavonoid seperti flavonol, flavonon, dan xanton akan memberikan warna merah jika direduksi dengan logam magnesium dan asam klorida. Warna merah yang terbentuk merupakan garam flavilium. Hal ini diperkuat oleh Harborne (1987) senyawa flavonoid seperti flavon dan flavonol jika direduksi dengan serbuk $\mathrm{Mg}$ dan $\mathrm{HCl}$ pekat mengahasilkan warna merah. Identifikasi senyawa Identifikasi senyawa dilakukan dengan menggunakan spektrofotometri UV-Vis dan IR. Identifikasi spektrofotometri UV-Vis bertujuan meramalkan transisi elektron valensi dari isolat yang dianalisis. Spektra hasil analisis spektrofotometri UV-Vis (Gambar 2).

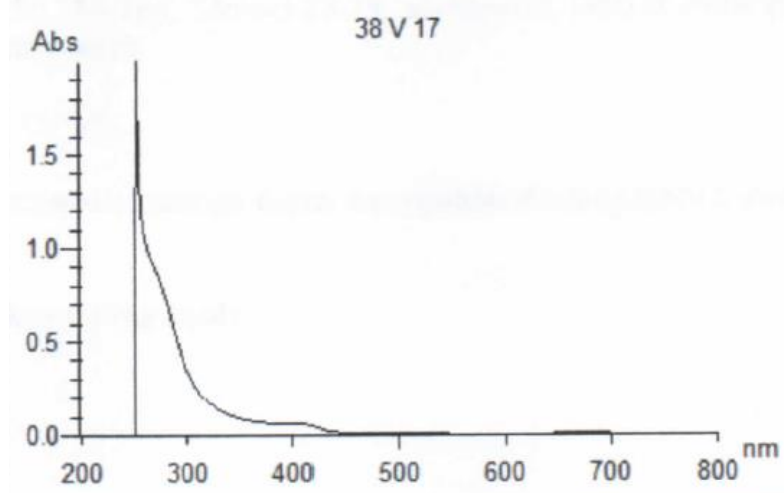

Gambar 2. Spektra isolat hasil analisis UV-Vis

Berdasarkan hasil spectra UV-Vis serapan pada panjang gelombang 250 nm di duga karena adanya transisi elektron yang tidak berikatan ke orbital $\sigma$ anti-ikatan $\left(n \rightarrow \sigma^{*}\right)$ oleh suatu ausokrom yang tidak terkonjugasi yang diduga merupakan gugus fungsional hidroksil (OH). Hal ini diperkuat dalam Khopkar (2014) transisi elektron yang tidak berikatan 
ke orbital $\sigma$ anti-ikatan $\left(n \rightarrow \sigma^{*}\right)$ terjadi pada daerah $150-250 \mathrm{~nm}$.

Berdasarkan hasil identifikasi menggunakan spektrofotometer UVVis, isolat menunjukkan senyawa flavonoid. Dalam Markham (1988) senyawa flavonol memiliki pita II pada kisaran panjang gelombang 250-280 $\mathrm{nm}$ sedangkan senyawa khalkon memiliki pita II pada kisaran panjang gelombang 230-270 nm dengan intensitas rendah.

Spektra hasil analisis menggunakan spektrofotometri inframerah (IR) ditunjukkan pada Gambar 3.

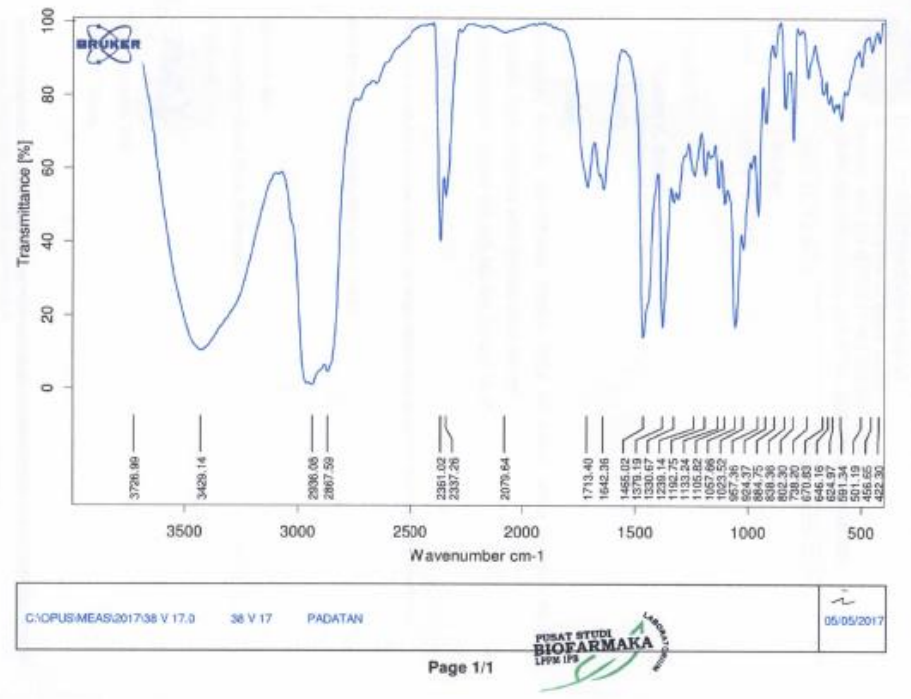

Gambar 3. Spektrum isolat hasil analisis spektrofotometer inframerah (IR)

Berdasarkan data hasil analisis memperoleh data spektrum senyawa. spektrofotometer inframerah (IR) yang Adapun hasil analisis spektrum berupa spektrum dianalisis untuk 
inframerah (IR) isolat dari ekstrak etil asetat disajikan pada Tabel 1.

Tabel 1. Analisis spektrum inframerah (IR) isolat

\begin{tabular}{|c|c|c|c|c|c|c|}
\hline \multicolumn{4}{|c|}{ Bilangan Gelombang $\left(\mathrm{cm}^{-1}\right)$} & Bentu & Intensit & Kemungkin \\
\hline Isolat & $\begin{array}{l}\text { Sukadan } \\
\mathrm{a},(2010)\end{array}$ & $\begin{array}{l}\text { Pustaka } \\
\text { (Creswell } \\
\text {, dkk, } \\
\text { 1981) }\end{array}$ & $\begin{array}{c}\text { Pustaka } \\
\text { (Silverstei } \\
\text { n,dkk., } 198 \\
4)\end{array}$ & k pita & as & $\begin{array}{c}\text { an gugus } \\
\text { fungsi }\end{array}$ \\
\hline 3429,14 & $\begin{array}{l}3000- \\
3500\end{array}$ & $\begin{array}{l}3000- \\
3750\end{array}$ & $\begin{array}{l}3550- \\
3200\end{array}$ & Lebar & Kuat & $\begin{array}{c}\text { Ulur } \\
\mathrm{OH} \\
\text { terikat }\end{array}$ \\
\hline 2936,08 & $2800-$ & $2700-$ & $2830-$ & Lebar & Lemah & Ulur C- \\
\hline 2867,59 & 2950 & 3000 & 2695 & Lebar & Lemah & $\begin{array}{c}\mathrm{H} \\
\text { Alifatik }\end{array}$ \\
\hline $\begin{array}{r}2361,02 \\
2337,06 \\
2079,64\end{array}$ & - & - & - & $\begin{array}{l}\text { Tajam } \\
\text { Tajam } \\
\text { Lebar }\end{array}$ & $\begin{array}{c}\text { Kuat } \\
\text { Lemah } \\
\text { Lemah }\end{array}$ & - \\
\hline 1713,04 & $\begin{array}{l}1700- \\
1725\end{array}$ & $\begin{array}{l}1500- \\
1675\end{array}$ & $1870-1540$ & Tajam & Sedang & Ulur $\mathrm{C}=\mathrm{O}$ \\
\hline $\begin{array}{l}1642,37 \\
1465,02\end{array}$ & $\begin{array}{l}1400- \\
1650\end{array}$ & $\begin{array}{l}1675- \\
1500\end{array}$ & $\begin{array}{l}1675- \\
1500\end{array}$ & $\begin{array}{l}\text { Tajam } \\
\text { Tajam }\end{array}$ & $\begin{array}{c}\text { Sedang } \\
\text { Kuat }\end{array}$ & $\begin{array}{l}\text { Ulur } \mathrm{C}=\mathrm{C} \\
\text { Aromatik }\end{array}$ \\
\hline 1379,17 & - & 1330- & 1330 & Tajam & Kuat & Tekuk C-H \\
\hline
\end{tabular}




\begin{tabular}{|c|c|c|c|c|c|c|}
\hline \multicolumn{4}{|c|}{ Bilangan Gelombang $\left(\mathrm{cm}^{-1}\right)$} & \multirow{2}{*}{$\begin{array}{l}\text { Bentu } \\
\text { k pita }\end{array}$} & \multirow{2}{*}{$\begin{array}{l}\text { Intensit } \\
\text { as }\end{array}$} & \multirow{2}{*}{$\begin{array}{l}\text { Kemungkin } \\
\text { an gugus } \\
\text { fungsi }\end{array}$} \\
\hline Isolat & $\begin{array}{l}\text { Sukadan } \\
a,(2010)\end{array}$ & $\begin{array}{c}\text { Pustaka } \\
\text { (Creswell } \\
\text {, dkk, } \\
\text { 1981) }\end{array}$ & $\begin{array}{c}\text { Pustaka } \\
\text { (Silverstei } \\
\text { n,dkk., } 198 \\
4)\end{array}$ & & & \\
\hline 1330,67 & & 1420 & & Tajam & Lemah & Alifatik \\
\hline 1239,14 & $1000-$ & $1000-$ & $1000-$ & Tajam & Sedang & Tekuk C- \\
\hline 1192,75 & 1300 & 1260 & 1300 & Tajam & Lemah & O Alkohol \\
\hline 1133,24 & & & & Tajam & Lemah & \\
\hline 1105,82 & & & & Tajam & Lemah & \\
\hline 1023,52 & & & & Tajam & Kuat & \\
\hline 957,36 & $650-1000$ & $650-1000$ & $840-800$ & Tajam & Sedang & Tekuk \\
\hline 924,37 & & & & Tajam & Lemah & $=\mathrm{C}-\mathrm{H}$ \\
\hline 884,75 & & & & Tajam & Kuat & $\begin{array}{c}\text { Aromati } \\
\text { k }\end{array}$ \\
\hline
\end{tabular}

Dari interpretasi data spektra inframerah menunjukkan adanya gugus fungsi $\mathrm{OH}$ terikat, $\mathrm{C}=\mathrm{O}, \mathrm{C}=\mathrm{C}$ aromatik, C-H alifatik, C-O alkohol dan $\mathrm{C}-\mathrm{H}$ aromatik yang merupakan ciri khas senyawa flavonoid. Berdasarkan struktur dasar jenis flavonoid pada Gambar 2.5, antara senyawa khalkon dan flavonol, hanya khalkon yang memiliki ikatan $\mathrm{C}-\mathrm{H}$ pada rantai alifatik sedangkan flavonol tidak memiliki rantai alifatik. Dengan demikian berdasarkan hasil identifikasi spektra UV-Vis dan inframerah isolat dari ekstrak etil asetat daun kelor mengandung senyawa flavonoid yang merujuk pada flavonoid jenis khalkon. 


\section{SIMPULAN}

Ekstrak metanol daun kelor mengandung senyawa flavonoid yang diduga adalah jenis khalkon yang diisolasi dengan menghasilkan noda tunggal yang positif terhadap uji flavonoid dan diidentifikasi dengan spektrofotometri UV-Vis dan spektrofotometri Inframerah (IR).

\section{DAFTAR PUSTAKA}

Achmad, Sjamsul Arifin. 1986. Kimia Organik Bahan Alam. Penerbit Karunika. Jakarta

Creswell, Clifford J., Olaf A. Runquist, dan Malcolm M. Campbell. 2005. Analisis Spektrum Senyawa Organik. ITB. Bandung

Fessenden, Ralph J., dan Joan S. Fessenden.1986. Organic Chemistry. 3rd. Wadsworth, Inc. California. Terjemahan Aloysius Hadyana Pudjaatmaka. 1998.
Kimia Organik. Edisi 3. Jilid 1. Erlangga. Jakarta.

Immy Suci Rohyani, Evi Aryanti, Suripto.(2015). Kandungan fitokimia beberapa jenis tumbuhan lokal yang sering dimanfaatkan sebagai bahan baku obat di Pulau Lombok. (jurnal Volume 1, Nomor 2, April 2015, ISSN: 2407-8050. Halaman: 388-391).

Harborne, J.B. 1987. Metode Fitokimia, Penuntun Cara Modern Menganalisis Tumbuhan. Penerjemah: Padmawinata, K. Terbitan kedua. Institut Teknologi Bandung. Bandung.

Khopkar, S.M. 2014. Konsep Dasar Kimia Analitik. Penerjemah: Saptorahardjo, A. UI press. Jakarta

Lutfiana. 2013. Uji Aktivitas Antiimflamasi Eksrtak Daun Kelor (Moringa oleifera Lamk.) Dengan Metode Stabilisasi Membrane Sel 
Darah Merah Dengan Metode In Vitro. (Skripsi). Jakarta : UIN Syarif Hidayatullah.

Sangi, M.; Runtuwene, M.R.J.; Simbala, H.E.I. dan Makang, V.M.A.2008. Analisis Fitokimia Tumbuhan Obat di Kabupaten Minahasa Utara.Chemistry Progress. 1,47-53.

Sastrohamdjojo, H. 1996. Sintesis Bahan Alam. UGM.Yogyakarta

Silverstein, Bassler dan Morril. 1984. Penyidikan Spektrofotometrik Senyawa Organik Edisi ke-4. Jakarta; Erlangga.
Sukadana, I M. 2010. Aktivitas Antibakteri Senyawa Flavonoid dari Kulit Akar Awar-Awar. 4 (1) : 63-67

Wiwit Denny Fitriana, Sri Fatmawati, dan Taslim Ersam. 2015. Uji aktivitas antioksidan terhadap $D D P H$ dan ABTS dari fraksi-fraksi daun kelor (Moringa oleifera). (jurnal Prosiding Simposium Nasional Inovasi dan Pembelajaran Sains 2015 (SNIPS 2015) 8 dan 9 Juni 2015. Bandung. 